\title{
Survivor?...The problem with labeling paediatric brain tumour "survivors"
}

\author{
Angela Zwiers
}

University of Western Ontario

'Survivor' is a common English word used in the context of health, natural disasters, social dilemmas, or even reality television shows. The term survivor describes a person with a heroic disposition, who has overcome adversity. It is important to consider the specific context and life experience of each individual when labeling him/her a survivor. Written from the perspective of someone who has endured a paediatric brain tumour, this paper explores 1) the definition and meaning of the word survivor; 2) why the word 'survivor' should be used cautiously in labeling people; and 3) alternative words that better fit those who have endured a paediatric brain tumour.

"The concept of cancer survivorship appears frequently in literature across disciplines but does not seem to have any precise definition or meaning." ${ }^{1}$ From an oncology perspective, a survivor is "someone who is living after a cancer diagnosis for five years or longer". In the context of a paediatric brain tumour, diagnosis and treatment only mark the beginning of an endless battle. When the term 'survivor' is used, it is common to falsely assume a sense of 'cure' 3 . Despite living after diagnosis, a paediatric brain tumour survivor is far from cured. Many suffer from subsequent tumour- and treatmentrelated effects and remain at risk for tumour recurrence long after diagnosis and treatment. "It's like sweeping

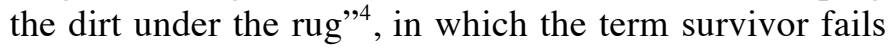
to describe the struggles experienced well after five years from the patient's initial diagnosis. An extensive list of late effects experienced by those who have had a paediatric brain tumour can be found in any research article on the topic ${ }^{5-7}$.

'Survivor' may be a misleading term and a misnomer. One must consider the frequency and ease at which the term survivor is used under different contexts. One can be a survivor in the context of cancer, a car accident, domestic violence or many other traumatic events. The term survivor does not predicate what one has survived. Someone who has won a reality television game show on a deserted island is identified as a survivor, as is someone who has undergone brain surgery, several rounds of chemotherapy and physical therapy to regain functional abilities. While the television 'survivor' wins a million dollars, the paediatric brain tumour 'survivor' faces several chronic physical, psychological, and social health problems for life. Is it appropriate to categorize all those who overcome any sort of adversity under a single umbrella term? With such common application, the term 'survivor' may have a minimizing or devaluating effect on the struggles paediatric brain tumour patients endure. The two cannot be equated and placed in the same survivor category. "It's...the categorizing of people to such a broad extent that we just need to pull back from that... and really look at it [survivor] on a situation by situation basis." 8

There is a need for "a fundamental reworking of public and medical discourse around what it is to be a cancer survivor - a rewriting of the survival script." ${ }^{\prime \prime}$ In some cancer studies, the terms 'healthy survivor', 'thriver' or 'warrior' are used as alternatives to survivor ${ }^{10}$. The term 'healthy survivor' refers to someone who is no longer at risk for recurrence and living with a healthy sense of body, mind and spirit. 'Thriver' refers to one who is still at risk for recurrence and still struggling on a daily basis with chronic health issues. The term 'warrior' refers to one who is still at risk for recurrence, but actively fighting to gain a healthy sense of body, mind and spirit. 'Warrior' may also be quite fitting as it encompasses the constant battle. "Anybody who has fought a brain tumour [is] a brain tumour warrior." 11 Whatever term is used, it should clearly reflect the individual's perspective of his/her current health state as well as his/her ongoing struggles. 
It is important to understand the meaning of the term 'survivor' in order for those who endured a paediatric brain tumour to facilitate development of a healthy identity. Brain tumour and other cancer survivors tend to embody the experience of their illness, identifying themselves based on their experiences, treatments, and resulting consequences ${ }^{12}$. Concerns over body image, sense of self, identity, and role in the social world plague young cancer patients, including those faced with a paediatric brain tumour. Former patients often struggle with learning disabilities, social skills, team participation, development of relationships, and other activities that contribute to shaping one's identity early in life ${ }^{13}$. Forming a healthy identity with a clear knowledge of what it means to be 'survivor' can help former patients develop their sense of self throughout life after illness.

My hope is that researchers, medical professionals, and even individuals who have suffered a paediatric brain tumour, consider the meaning of the term 'survivor' before labeling a participant, patient or themselves. Despite its positive connotation, use of the word survivor can be misleading in this instance, implying a sense of 'cure' and discounting the ensuing struggles likely to be encountered in the future. Alternative terms that better reflect the life of a paediatric brain tumour 'survivor' were discussed in this article to shed light on the topic of stereotyping those who have endured this type of cancer. This piece was written by a 'thriver'; a Masters student who was diagnosed with a paediatric brain tumour at age 16.

\section{References}

1 Doyle, N. (2008). Cancer survivorship: Evolutionary concept analysis. Journal of Advanced Nursing, 62(4), 499-509.

2 Feuerstein, M. (2007). Defining cancer survivorship. Journal of Cancer Survival, 1, 5-7.

3 Drew, S. (2003). Self-reconstruction and biographical revisioning: Survival following cancer in childhood or adolescence. Health: An Interdisciplinary Journal for the Social Study of Health, 7(2), 181-199.

4 Zwiers, A. (2011). [Quote from participant \#1 during qualitative research interview session]. Unpublished raw data.

5 Langeveld, N. E., Ubbink, M. C., Last, B. F., Grootenhuis, M. A., Voute, P. A., \& De Haan, R. J. (2003). Educational achievement, employment and living situation in long-term young adult survivors of childhood cancer in the Netherlands. Psycho-oncology, 12, 213225.
6 Fuemmeler, B. F., Elkin, T. D., \& Mullins, L. L. (2002). Survivors of childhood brain tumors: Behavioral, emotional, and social adjustment. Clinical Psychology Review, 22, 547-585.

7 Diller, L., Chow, E. J., Gurney, J. G., Hudson, M. M., Kadin-Lottick, N. S., Kawashima, T. J., et al. (2009). Chronic disease in the childhood cancer survivor study cohort: A review of published findings. Journal of Clinical Oncology, 27(14), 2339-2355.

8 Zwiers, A. (2011). [Quote from participant \#4 during qualitative research interview session]. Unpublished raw data.

9 Drew, S. (2007). 'Having cancer changed my life, and changed my life forever': Survival, illness legacy and service provision following cancer in childhood. Chronic Illness, 3, 278-295.

10 Harpham, W. S. (2008). A healthy survivor. Oncology Times, 30(4), 36.

11 Zwiers, A. (2011). [Quote from participant \#3 during qualitative research interview session]. Unpublished raw data.

12 Prouty, D., Ward-Smith, P., \& Hutto, C. J. (2006). The lived experience of adult survivors of childhood cancer. Journal of Pediatric Oncology Nursing, 23(3), 143-151.

13 Carlson-Green, B. (2009). Brain tumor survivors speak out. Journal of Pediatric Oncology Nursing, 26(5), 266279.

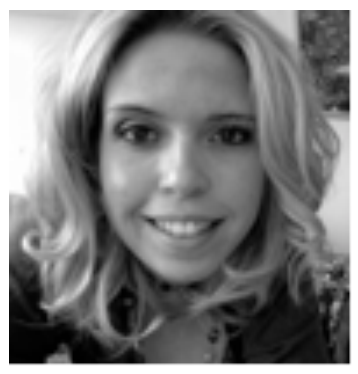

Author Profile

Angela Zwiers is a M.Sc. candidate in Health and Rehabilitation Sciences at the University of Western Ontario. Her qualitative study investigates the meaning of 'survivor' as constructed by young adults who have had a paediatric brain tumour. Angela is also interested in pursuing a Ph.D. in neuroscience and psychosocial oncology research. 